\title{
Real-time Machine Health Monitoring System using Machine Learning with loT Technology
}

\author{
Tzen Ket Wong ${ }^{1}$, Hou Kit Mun ${ }^{1,}$, Swee King Phang ${ }^{1}$, Kai Lok $\mathrm{Lum}^{1}$ and Wei Qiang Tan ${ }^{2}$ \\ ${ }^{1}$ Taylor's University, 1, Jalan Taylors, 47500 Subang Jaya, Selangor, Malaysia \\ ${ }^{2}$ GoAutomate Sdn Bhd, 33, Jalan Pentadbir U1/30, Taman Perindustrian Batu 3, 40150 Shah Alam, \\ Selangor, Malaysia
}

\begin{abstract}
Machine health monitoring is the main focal point for now as many industries are evolving to industry 4.0. Industry 4.0 is the revolution in industrial that involve the Internet of Things (IoT) and artificial intelligence toward automation and data sharing for production efficiency improvement. The existing established methods for machine health monitoring were not in real-time and there was no real-time correction of data from the load and processing of data on the computer. In tracking machine health efficiency this approach wasn't very successful. Real-time machine health monitoring can improve overall equipment effectiveness (OEE), reduce electricity consumption, minimize unplanned downtime, and extend machine lifetime. In this research paper, we propose to design a real-time machine health monitoring system using machine learning with IoT technology that can analyze the supply balancing condition on a 3phase system. This system is built with compact physical hardware and can capture the electrical data from the load then send it to the server. The server will progress data and train the data using machine learning. The system was installed on a blender machine in a factory. In this research, a system which is able to monitor the machine operation and classify the operation stages of the machine was developed. Besides that, the system also capable to monitor the load balancing condition of the machine.
\end{abstract}

\section{Introduction}

Most of the industry nowadays is evolving to industry 4.0 and need to adopt the internet of thing (IoT) technology to keep competitive. Industry 4.0 is the movement towards automation and data sharing in industrial technology and processes that include the IoT, the Industrial Internet of Things (IIOT), cloud computing, and artificial intelligence. Artificial intelligence is capable of performing tasks that substitute human intelligence, which can be known as machine learning. Last decade, machine health inspection is highly relying on human power. Consequently, there will be more automation technology in the factory for machine health inspection to reduce human power.

Based on the research by G.K. Singh and S. A. S. Al Kazzaz [1], they had developed an intelligent diagnostic system using the $\mathrm{C}++$ programming language and MATLAB for

\footnotetext{
* Corresponding author: houkit.mun@taylors.edu.my
} 
induction machine health monitoring in 2008. This intelligent diagnostic system unable to perform real-time monitoring. The architecture of this machine learning is a multi-layer feed-forward neural network, which needs many machine's input parameters for model training. That paper introduces 17 different models to diagnose the health of the machine and the final system able to detect the machine's fault with efficiency range from $81.8 \%$ to $100 \%$ for different types of faults and conditions as shown in Table 1 . In the current times, most of the high cost industrial motors have pre-installed with some sensors such as vibration and temperature sensors inside the machine to monitor the motor behavior and trigger a warning signals or shutting down the system for preventing any catastrophic failure [2].

Table 1. Diagnostic efficiency of different machine conditions. [1]

\begin{tabular}{llc}
\hline & Phenomena & $\begin{array}{c}\text { Diagnostic } \\
\text { Efficiency }\end{array}$ \\
\hline Condition detection & Supply condition & $100 \%$ \\
& Supply harmonics & $100 \%$ \\
& Machine health & $100 \%$ \\
\hline Fault classification & Supply unbalanced & $100 \%$ \\
& Bearing faults & $95 \%$ \\
& Mechanical unbalances and coupling faults & $95 \%$ \\
& Over/under voltage & $95 \%$ \\
\hline Fault level estimation & Supply condition & $87.5 \%$ \\
& Supply harmonic & $92.3 \%$ \\
& Dry bearing fault & $81.8 \%$ \\
\hline
\end{tabular}

Other than that, voltage unbalanced at motor stator terminals leads to a shorter life span of the system and deterioration of its output due to increased losses, unbalanced line currents, and excessive heating [3]. For larger three-phase motors, they will draw equivalent power from each phase of the three phases in the main supply, however, this situation will not happen frequently. Unbalanced supply and harmonics can lead to instability of the motor in which will reduces its efficiency and lifespan. Unbalanced in single-phase loads may also cause malfunctions [4]. Therefore, the system in the research was designed with the feature that able to detect the unbalanced supply.

The 3-phase system is separated into balanced and unbalanced systems. In an ideal balanced system, the waveform is perfectly sinusoidal, the magnitude and phase shift of $120^{\circ}$ or $\mathrm{T} / 3$ is different, as shown in Figure 1 . Besides, the current flowing through each phase is the same and no current flows through the neutral. Furthermore, the power loss is very low or has no presence in an ideal case. However, most of the system or loads are unbalanced systems and it is easy to achieve an unbalanced system where either phase A, phase B, or phase $\mathrm{C}$ have different loads on each other's phase. Two main factors cause an unbalanced system. The first is unbalanced in the winding of 3-phases equipment like a 3phase induction motor. The reason for this is that if the reactance of the three windings is different then it will draw unequal current from the system. The second factor is the unequal load on the system. This will cause more current to flow through one particular phase. Both factors will cause the 3-phase machine to overheat and decrease its overall lifespan. Other than that, this will also cause power loss as known $I^{2} R$ [5].

Furthermore, the machine health monitoring system is very popular now and has attracted many researchers to research in this field. Most of the methods that were used for machine health monitoring system mainly focused on the motor fault, such as stator [6], rotor bars [7], static and dynamic air gap [8], bent shaft, misalignment, bearing and gearbox failures [9]. All these faults needed a specific sensor or calculation to detect it or some needed humans to analyze. Other than that, the vibration sensor also known as 
accelerometer was a common sensor for most of the researchers to use to detect the vibration signal to analyze the fault of the motor [10]. Micro Electromechanical Systems (MEMS) is an accelerometer that has merits of low-cost, high reliability, and low power consumption where compare to another accelerometer [11]. The limitation of this work was the data input was limited to one which was the MEMS accelerometer. Only using one input data to detect the electrical fault was not very reliable, although the result was very close to the actual result. Other than that, this method only can diagnose a 3-phase induction motor which market usable to all industry. In addition, all the aforementioned machine health monitoring system were lack of wireless monitoring capability.

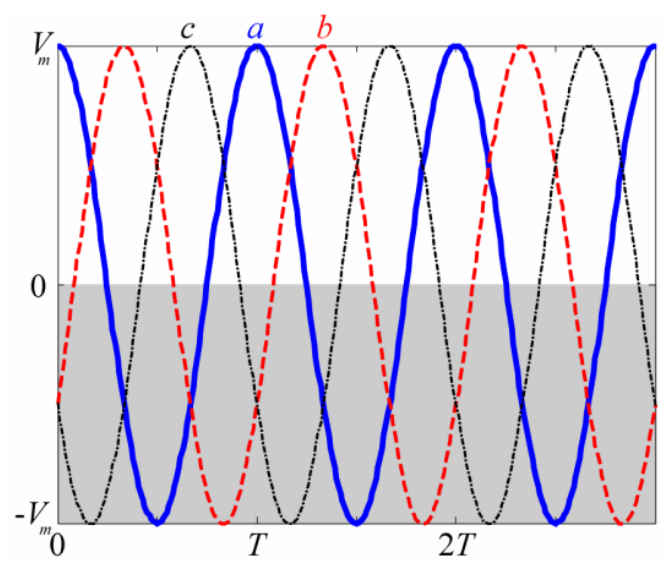

Fig. 1. 3-phase sinusoid waveform.

R. Udayakumar and V. Khanaa [12] developed a health monitoring system of electrical machines based on the wireless network (ZigBee/ IEEE 802.15.4). The limitation of the ZigBee is only a Wi-Fi transmission platform, it needs a transmitter and a receiver to complete the data transfer thought Wi-Fi. Other than that, the data still needs to be processed under a computer. The system still needs the physical wire to connect to the computer to progress the data. In this study, a completely wireless system is developed, and the machine health condition could be monitored anywhere as long as we have internet access with any electronic devices. Real-time data is important in order to make strategic business decisions. Instead of just weeks or months, product trends may need to be measured over days or hours.

\section{Methodology}

The whole research methodology was stated in the flow chart as shown in Figure 2, there have 4 different stages to follow the timeline of the entire project. In the first stage, the machine fault and machine learning were carried out to do more research work and more understand the structure. Come to the second stage, the circuit construction of the physical hardware was carried out. The final electronic components that were selected for this research were the ESP 01 as the Wi-Fi module and PZEM-004T V3 as the sensor to capture the electrical data. At stage three, the accuracy of the sensor was carried out and the accuracy was up to $95 \%$ accurate compare to multi-meter. Lastly, stage four was machine learning development and present all the outcome of this research project. The result was present on the webpage and can monitor the machine data in real-time. 


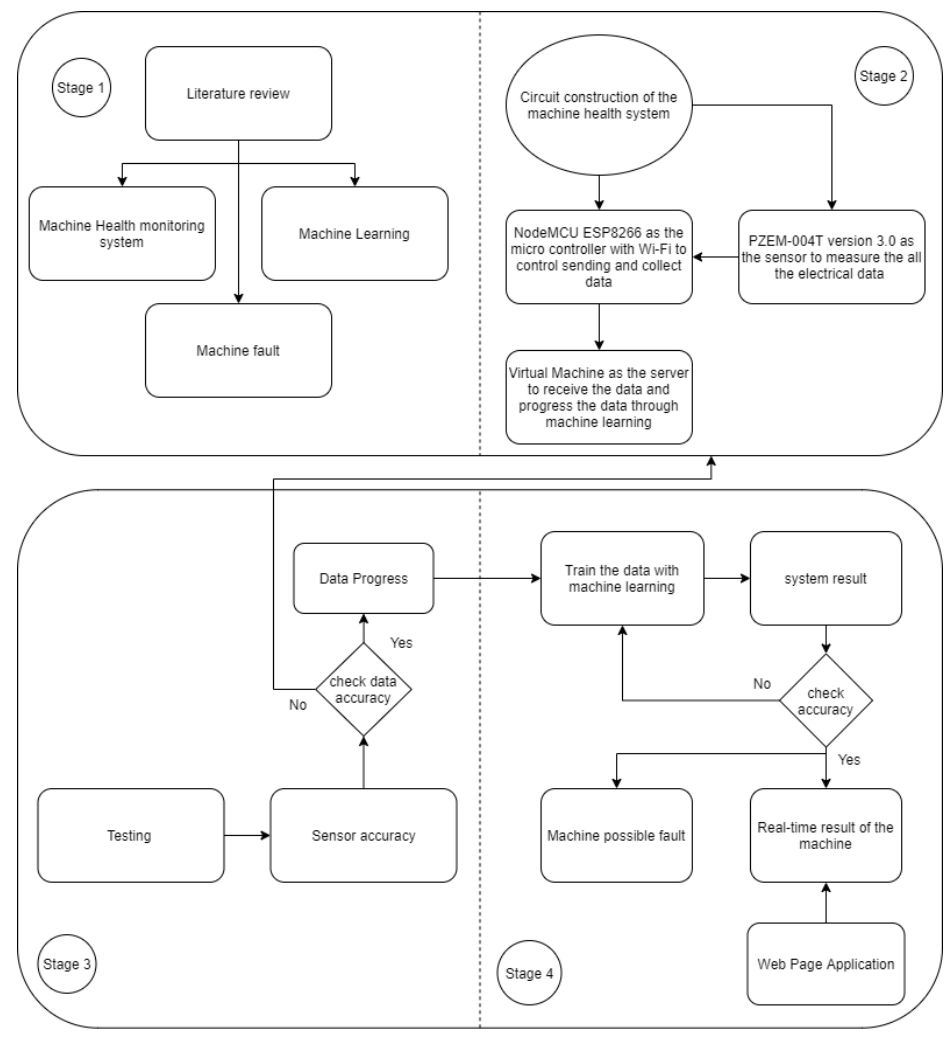

Fig. 2. Flow chart of the research methodology.

\subsection{Setup for hardware}

The setup of this research was only two modules which were the sensor and the current transformer (CT). First, connect the line and neutral line to the sensor then the CT clip on the life wire of the load. Second, wait for the sensor to power up then connected to the WiFi. The complete physical model of the sensor was completely constructed as shown in Figure 3.

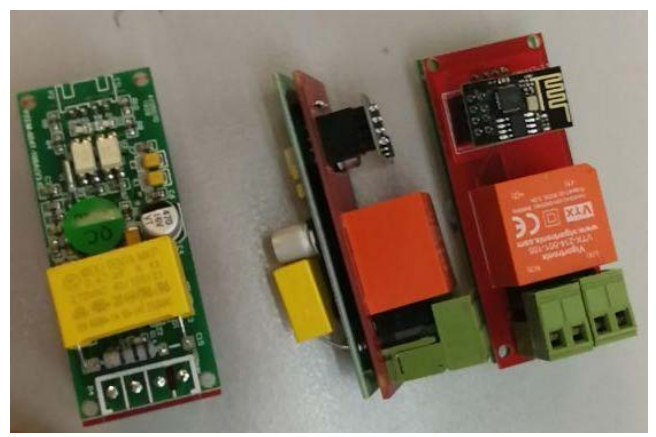

(a)

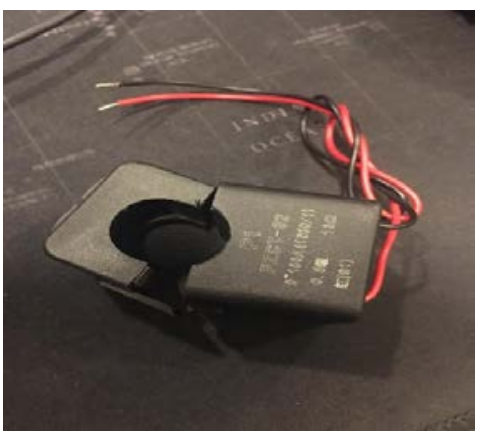

(b)

Fig. 3. The complete circuit of the physical hardware (a); Current transformer of this system (b) 
The actual machine set for this paper was the three-phase blender machine as shown in Fig 4, the machine was in the factory provided by GoAutomate Sdn. Bhd. Three sensor already installed inside the blender machine due to the blender is three-phases supply and the data cable to capture in the visual machine. The data captured every 2 seconds and save in the database. The visual machine is also provided by GoAutomate Sdn. Bhd.

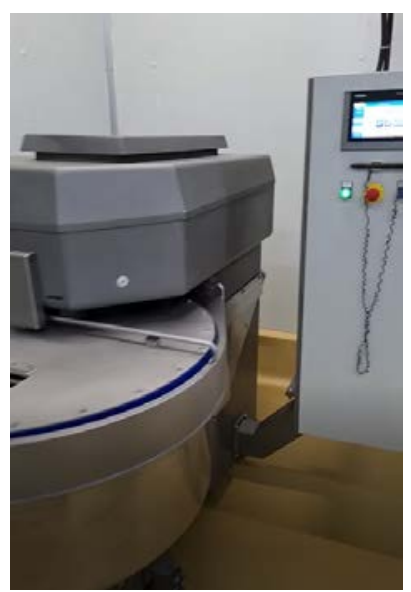

Fig. 4. Three-phase blender machine

\subsection{Artificial neutral network}

The neural network for load classification was created using Tensor-flow, by attempting to classify the stages based on the monitored data reading of several parameters, namely, the current, power, voltage and power factor of the stages during operation. The neural network is able to 'learn' by iterating across the training dataset to adjust the weights and biases in the neural network to achieve the desired output, an optimization function to define the cost or loss function as the network iterates. During the 'training' of the network, the network will have a loss or cost function to give a 'score' for itself in terms of the accuracy of the network. The 'score' or loss, is calculated by using the cross-entropy [13] of the known probabilistic distribution of a class and the generated probabilistic distribution output due to the soft-max function by the neural network. The overall visualisation of the neural network shape as shown in Figure 5.

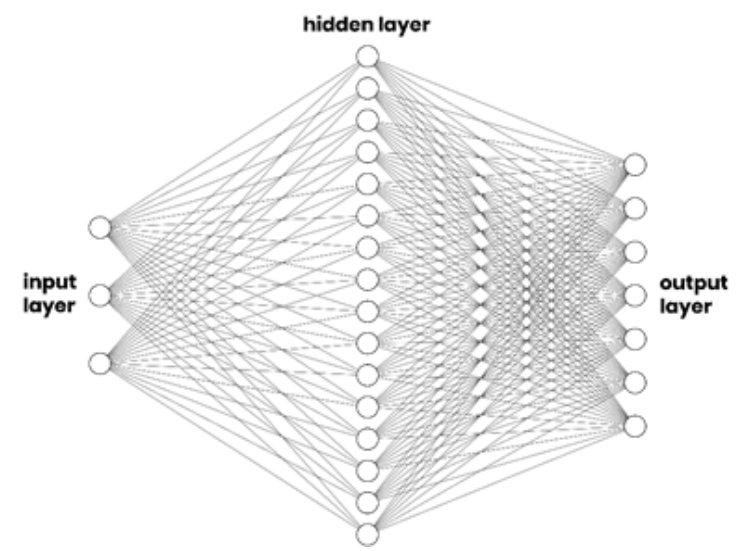

Fig. 5. Visualisation of the neural network shape. 


\subsection{Virtual machine}

A Virtual Machine (VM) is a computing resource that runs programs and deploys apps using software rather than a physical computer. This VM is provided by the universityindustry partner and the use of the VM is to store the data in the database. Other than that, $\mathrm{VM}$ is treated as the server for handling the data from the system and store the data into the database. The VM provided by the university-industry partner is running Linus operating systems where have a bit different user interface from the normal window operating system. XAMPP was chosen to use as my database apps as shown in Figure 6, because it is a free and open-source cross-platform and it is consisting mainly of the Apache HTTP Server, and MariaDB database. Furthermore, the Visual Studio Code was chosen as the back-end server and web-based apps as a development platform. It is a free source-code editor made by Microsoft for Windows, Linux, and macOS.

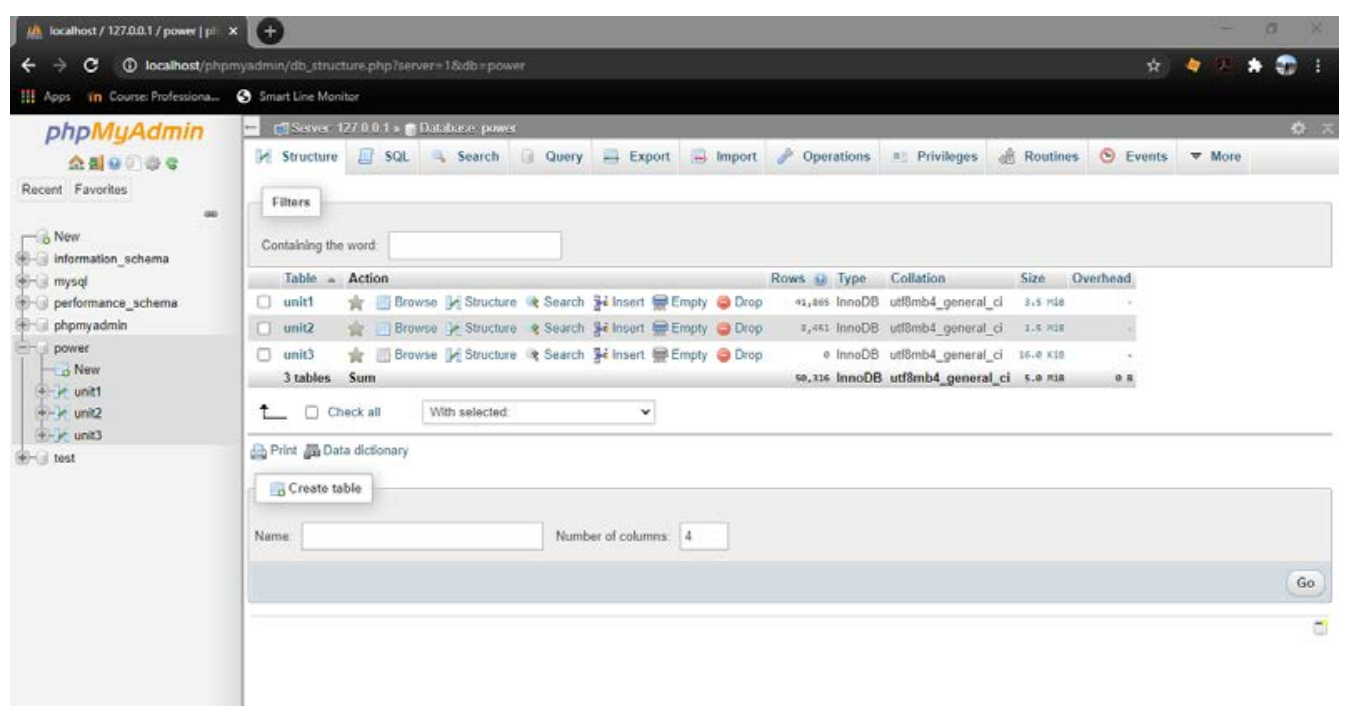

Fig. 6. Database user interface using XAMPP.

\section{RESULTS AND DISCUSSION}

The supply voltage of the three-phase blender machine was captured as shown in Figure 7. The data was captured during working time. The three-phase supply voltage were measured by three measurement units are presented in the graph where unit 1 represented phase 1 and unit 2 represent phase 2 and so on. Phase 1 and phase 2 were under the same range where between $226 \mathrm{~V}$ to $232 \mathrm{~V}$. For phase 2 was higher than phase 1 and phase 2 , the voltage range is between $232 \mathrm{~V}$ to $238 \mathrm{~V}$. It was slightly higher than another two phases.

Voltage imbalance can be estimated as the maximum deviation, expressed in percent, from the mean of the three-phase voltages divided by the mean of the three-phase voltages [14]. The formula shows in below,

$$
\text { voltage unbalance }=\frac{\max \text { deviation from average voltage }}{\text { average voltage }}
$$




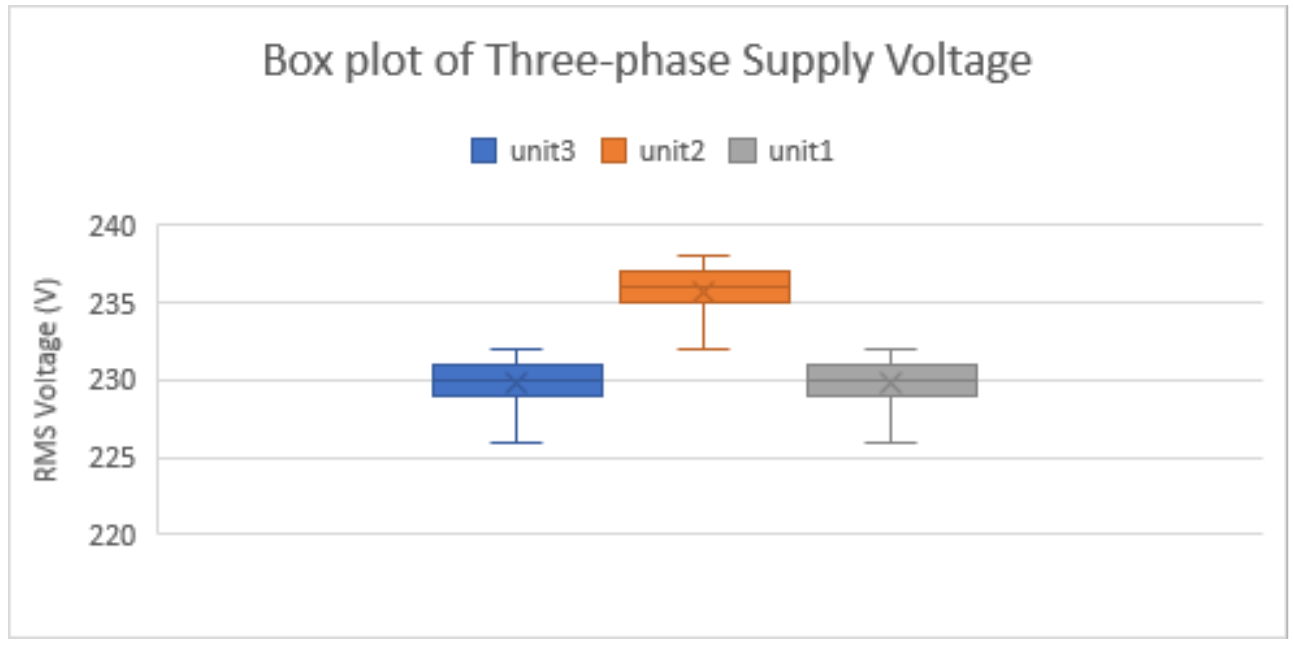

Fig. 7. Supply voltage of the three-phase blender machine.

The unbalance voltage of the machine was as shown in Table 2 below. It shows that the voltage unbalances of the blender machine is $0.86 \%$. By following the standard, the limit of the maximum of the voltage unbalance was 3\% [15]. This shows that the blender machine had a good supply voltage as the voltage unbalance was $0.86 \%$ lower than $3 \%$.

Table 2. Unbalance voltage of the blender machine.

\begin{tabular}{lccc}
\hline & Phase 1 & Phase 2 & Phase 3 \\
\hline Voltage reading (V) & 230 & 236 & 230 \\
\hline Average voltage (V) & & 232 & \\
\hline $\begin{array}{l}\text { Maximum Deviation } \\
\text { from Average Voltage }\end{array}$ & 2 & \\
$(\mathrm{~V})$ & & \\
\hline $\begin{array}{l}\text { Voltage Unbalance } \\
(\%)\end{array}$ & & 0.86 & \\
\hline
\end{tabular}

As shown in Figure 8, all the three-phase RMS-current of the blender machine were recorded and compared with other data from the actual machine runtime. The first step in the operating process of the blender machine is to open the cover of the blender machine as the graph of small current spiked about $1 \mathrm{~A}$. The second stage is the dry mix, as the current rises to $15 \mathrm{~A}$ above, the motor is running at a slow speed. After the dry mix, the blender machine cover is open. Then the coming stage is the resting stage as the current was around $0 \mathrm{~A}$ and the mixing mode is showing stop mode. The blender machine will close the cover and then operate the low-speed motor in the third stage. The motor was operating at a slow speed of around 10 minutes, then the blender machine shifted to a high motor where the current rise from $18 \mathrm{~A}$ to $23 \mathrm{~A}$. The blender machine's motor stops working at the last stage, and the cover is open.

Six data types, dough temperature, the motor in fast or slow mode, the motor in run or stop mode, and RMS current of unit 1,2,3, were represented in the graph. When the blender machine was operating at a high speed, the current unexpectedly increased from 20 to $25 \mathrm{~A}$. It also has the same pattern compared to set 2 results as shown in Figure 9, which means that the health of the machine was in normal condition when the blender machine was 
running. The value of current was about $15-20 \mathrm{~A}$, equivalent to the engine when it was running at slow speed, and both set 1 and set 2 data were the same.

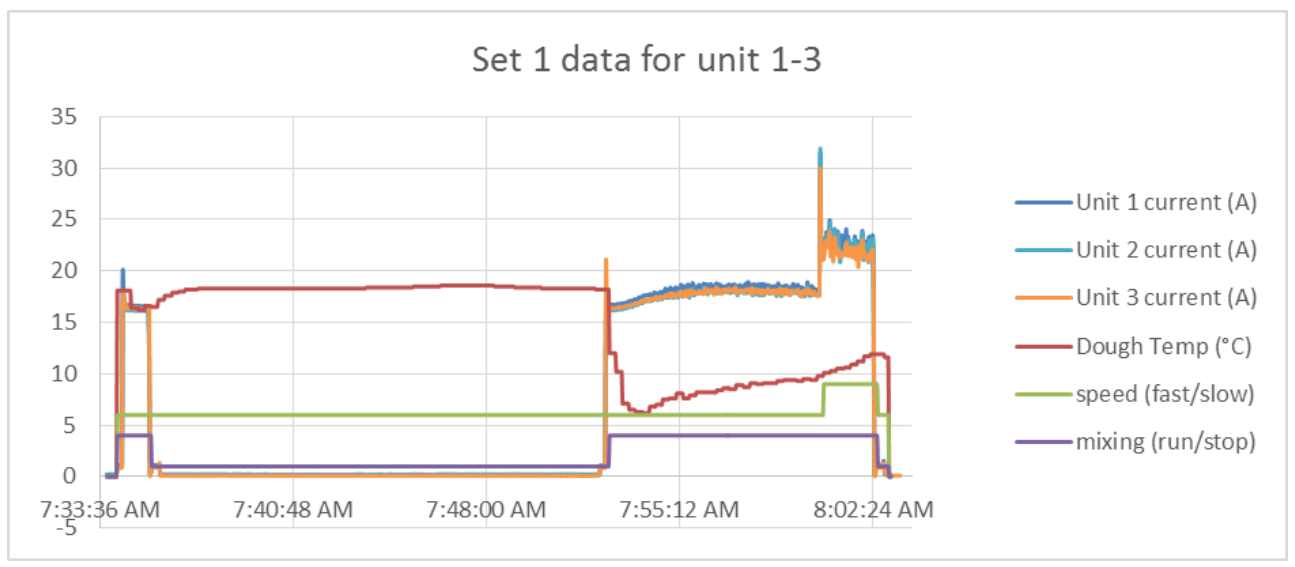

Fig. 8. Set 1 data for blender machine with the current value.

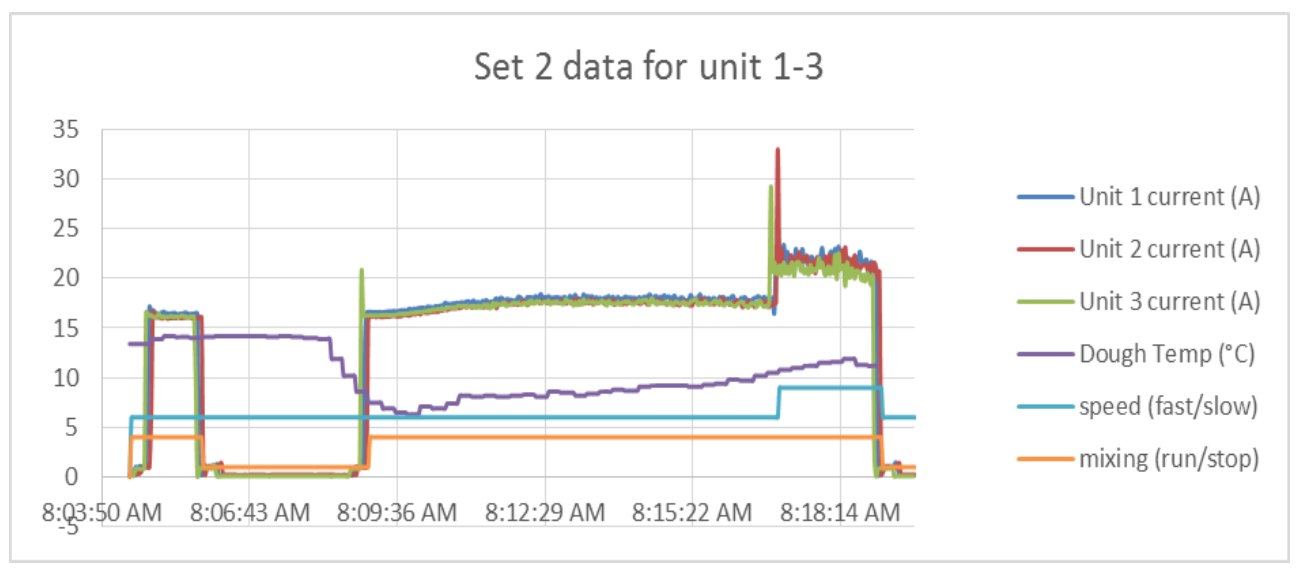

Fig. 9. Set 2 data for blender machine with the current value.

The average power factor of the blender machine during operation is shown in Table 3 below. From stage 1 to stage 5, five different stages represent different operating processes of the blender unit.

Table 3. The average power factor of the blender machine during operation.

\begin{tabular}{|c|c|c|c|c|c|c|}
\hline & & $\begin{array}{l}\text { Stage } 1 \\
\text { Open } \\
\text { Cover }\end{array}$ & $\begin{array}{l}\text { Stage } 2 \\
\text { Close } \\
\text { Cover }\end{array}$ & $\begin{array}{l}\text { Stage } 3 \\
\text { Slow Speed }\end{array}$ & $\begin{array}{l}\text { Stage } 4 \\
\text { High Speed }\end{array}$ & $\begin{array}{l}\text { Stage } 5 \\
\text { Dry mix }\end{array}$ \\
\hline $\begin{array}{l}\text { Average } \\
\text { Factor }\end{array}$ & Power & 0.68 & 0.75 & 0.87 & 0.52 & 0.96 \\
\hline
\end{tabular}

The operational process of the blender machine and during the corresponding current profile were clearly shown in Figure 10 . The power factor graph combines with other data of the blender machine was represent in Figure 11. 


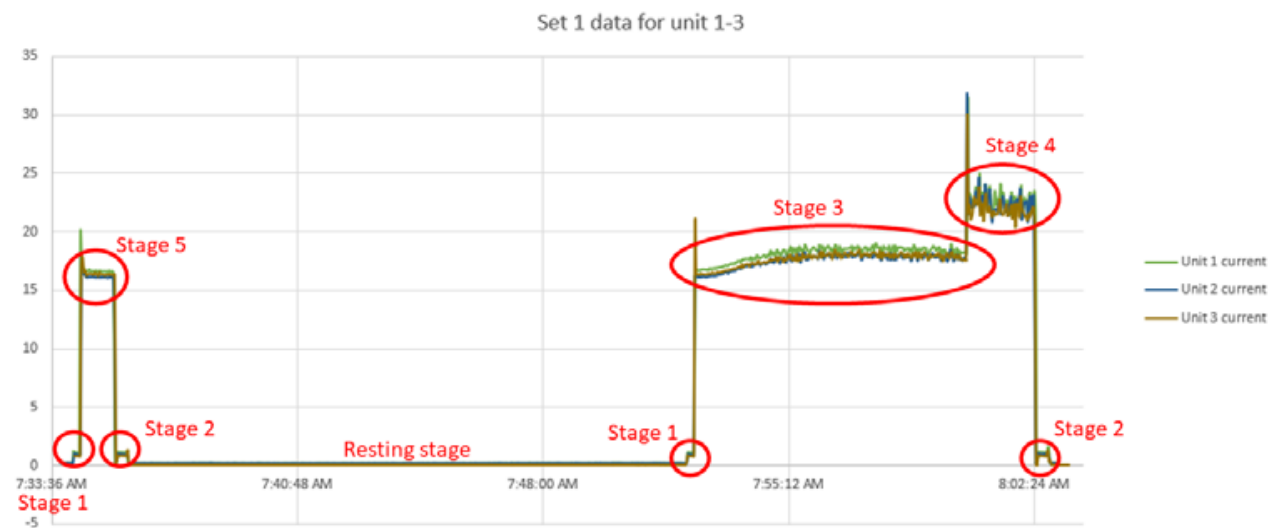

Fig. 10. Different stages of the blender machine during operation and corresponding current profile.

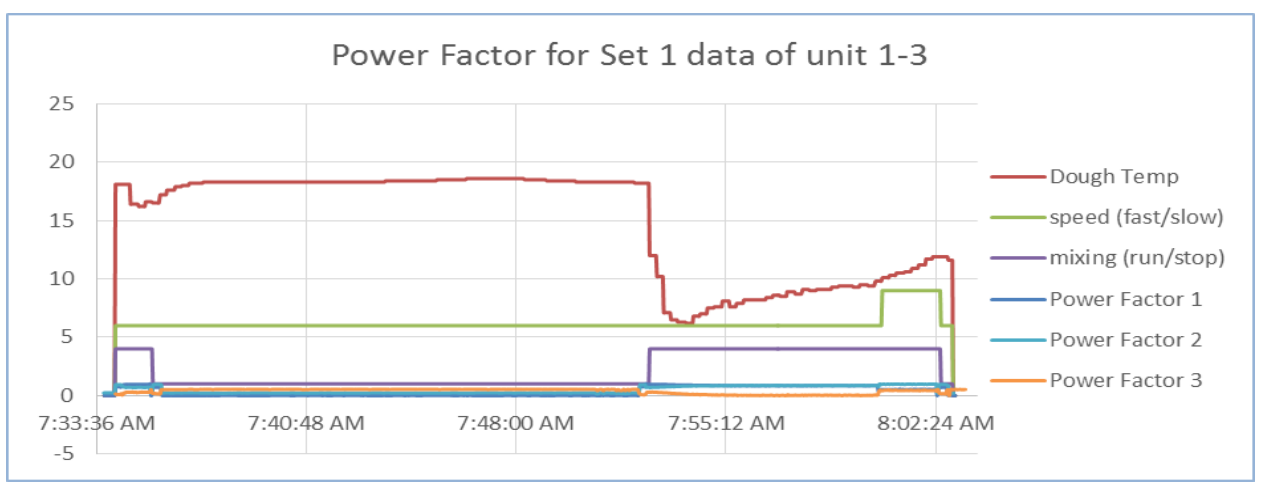

Fig. 11. Set 1 data for blender machine with power factor value.

\section{Conclusions}

This developed system can monitor a machine's health in real-time and able to identify the supply unbalanced fault in a 3-phases system. The first objective of this research was achieved as this system has compact physical hardware that can fit in most of the machines that are currently used in industries and the electrical data measurements is within with $95 \%-98 \%$ average accuracy. The second objective was also be achieved with an webbased interface was developed in which the user can monitor the machine condition through the website. The designed system is able to monitor the supplied voltage, current and power factor for different operation stages of the blender machine in real-time. Besides, the various operation process stages of the blender machine and supply unbalanced conditioned could also be identified by the system. The limitation of this system is it needs three measurement units to measure a 3-phase system.

Acknowledgement: The authors would like to acknowledge Taylor's University for support for this project. Other than that, authors would like to acknowledge GoAutomate Sdn Bhd. for providing all the testing resources and financial support for this research. 


\section{References}

1. G. K. Singh, S. Ahmed Saleh Al Kazzaz, IEEE Syst. J. 2, 273 (2008).

2. B. Lu, T. G. Habetler, R. G. Harley, 2005 IEEE Int. Conf. Electr. Mach. Drive. 1365 (2005).

3. S.M. Ahmed, H. Abu-Rub, S.S. Refaat, A. Iqbal, Int. J. Elect. Comp. Eng. 3, 129 (2013).

4. N. Lashkari, J. Poshtan, H. F. Azgomi, ISA Trans. 59, 334 (2015).

5. J.E. Williams, AIEE Trans. pt. III-A, Power Appar. Syst. 73, 125 (1954).

6. A. Siddique, G. S. Yadava, B. Singh, IEEE Trans. Energy Convers. 20, 106 (2005).

7. B. Bessam, A. Menacer, M. Boumehraz, H. Cherif, ISA Trans. 64, 241 (2016).

8. G. Mirzaeva, K. I. Saad, M. G. Jahromi, IEEE Trans. Ind. Appl. 53, 2657 (2017).

9. N. G. Lo, A. Soualhi, M. Frini, H. Razik, Proc. 13th IEEE Conf. Ind. Electron. Appl. 900 (2018).

10. S. B. Chaudhury, M. Sengupta, K. Mukherjee, Int. J. Sci. Eng. Res. 2347 (2014).

11. G. S. Maruthi, K. Panduranga Vittal, Proc. Int. Conf. Power Electron. Drive Syst. 2, 838 (2005).

12. R. Udayakumar, V. Khanaa, Int. J. Eng. Comp. Sci. 2, 1117 (2013).

13. K. Janocha, W. M. Czarnecki, On Loss Functions for Deep Neural Networks in Classification. arXiv preprint arXiv:1702.05659, (2017).

14. P. Pillay and M. Manyage, IEEE Power Eng. Rev. 21, 50 (2001).

15. Tenaga Nasional Berhad, "Electricity Supply Application Handbook," Distribution Network Division \& Retail Division. vol. 3.1, 2019. 